\title{
Study of dyslipidemia in patients with Obstructive Sleep Apnea Syndrome in primary health care
}

\author{
JOSÉ LUÍS FERRARO 1, 2 A-G, INÊS ROSENDO 1,3, 4, A-G, LUIZ MIGUEL SANTIAGO 1, 3, 5, A, D, E, G \\ ORCID ID: 0000-0002-7952-0468 ORCID ID: 0000-0001-8838-6021 ORCID ID: 0000-0002-9343-2827 \\ JOSÉ AUGUSTO SIMÕES 3, 4, 6, F, G \\ ORCID ID: 0000-0003-2264-7086 \\ ${ }^{1}$ Faculty of Medicine, University of Coimbra, Portugal \\ ${ }^{2}$ Hospital Beatriz Ângelo, Loures, Portugal \\ ${ }^{3}$ University Clinic of General Practice and Family Medicine of the University of Coimbra, Portugal \\ ${ }^{4}$ CINTESIS - Centre for Research in Health Technologies and Service (Oporto), Portugal \\ ${ }^{5}$ CEISUC - Centre for Health Studies and Research of the University of Coimbra, Portugal \\ ${ }^{6}$ Faculty of Health Sciences, University of Beira Interior, Covilhã, Portugal
}

A - Study Design, B - Data Collection, C - Statistical Analysis, D - Data Interpretation, E - Manuscript Preparation, F - Literature Search, G - Funds Collection

Summary Background. Obstructive Sleep Apnea Syndrome (OSAS) is associated with several morbidities. The most important ones are obesity, hypertension and diabetes mellitus. A clear relationship of OSAS and dyslipidemia is yet to be demonstrated.

Objectives. To evaluate the prevalence of dyslipidemia as a morbidity associated with OSAS and to understand its relationship with the severity of OSAS.

Material and methods. We randomly selected 92 patients diagnosed until the end of May 2016 with OSAS from two primary health care units and 184 patients as controls (no OSAS diagnosed) from random lists of patients matched in age and gender with patients with OSAS.

We calculated the prevalence of the classified comorbidities (overweight, hypertension, type 2 diabetes mellitus and dyslipidemia) in both groups. We used logistic regression to check the association between them. We evaluated the relationship between dyslipidemia and OSAS severity by using the Apnea/Hypopnea Index (AHI).

Results. The prevalence of dyslipidemia was $80 \%$ in patients with OSAS. Patients with OSAS were diagnosed as overweight (97\%), had arterial hypertension (89\%) and type 2 diabetes mellitus (43\%). OSAS was not independently related to type 2 diabetes mellitus $(p=0.101)$ and to dyslipidemia $(p=0.389)$. However, overweight and arterial hypertension were related independently to OSAS $(p<0.001)$ with a risk for OSAS. The prevalence of dyslipidemia in patients with mild, moderate and severe OSAS was $22 \%, 13 \%$ and $25 \%$, respectively.

Conclusions. Patients with OSAS have a high prevalence of dyslipidemia despite not being independently related. There were no statistical differences between patients with mild, moderate and severe OSAS.

Key words: sleep apnea syndromes, dyslipidemias, overweight, hypertension, diabetes mellitus type 2.

Ferraro JL, Rosendo I, Santiago LM, Simões JA. Study of dyslipidemia in patients with Obstructive Sleep Apnea Syndrome in primary health care. Fam Med Prim Care Rev 2021; 23(1): 13-16, doi: https://doi.org/10.5114/fmpcr.2021.103150.

\section{Background}

Obstructive Sleep Apnea Syndrome (OSAS) is the most common sleep disorder [1], and it is a significant source of morbidity and mortality [1-5]. It can be defined by transitory episodes of apnea, and it is characterized by the presence of sleep fragmentation and excessive daytime sleepiness associated with cardiovascular and neurocognitive disorders [6]. This syndrome relates to a state of chronic hypoxia caused by recurrent episodes of temporary total or partial obstruction of the upper airways during sleep $[2,6]$. OSAS affects around $4 \%$ of middle-aged men and $2 \%$ of middle-aged women in developed countries [2, 6]. In Portugal, the prevalence of OSAS is estimated, in the population of 25 years of age or more, to be around $0.89 \%$ [5]. It generally affects middle-aged, obese male individuals [5]. Several studies recognize OSAS as an independent risk factor for cardiovascular diseases $[2,6,7]$.

Dyslipidemia is one of the risk factors for atherosclerosis [8]. It is defined by an elevation of total cholesterol $(\geq 190 \mathrm{mg} / \mathrm{dl})$, a reduction of $\mathrm{HDL}$ ( $\leq 40 \mathrm{mg} / \mathrm{dl}$ in men and $\leq 45$ in women), an elevation of LDL ( $\geq 115 \mathrm{mg} / \mathrm{dl}$ ) and triglycerides ( $\geq 150 \mathrm{mg} / \mathrm{dl}$ ) [8]. The Portuguese prevalence of hypercholesterolemia is $47 \%$, and an elevation of LDL occurs in $38 \%$ [9]. Hypertriglyceridemia is less prevalent, affecting about $13 \%$ of the population [9].

Several comorbidities have been associated with OSAS, among them, cardiovascular complications [10]. In Portugal, the most frequent cardiovascular risk factors in patients with OSAS are arterial hypertension (75.9\%), obesity $(74.2 \%)$ and diabetes mellitus (34.1\%) [5].

Dyslipidemia has been studied as a comorbidity related to OSAS, but studies of such association are scarce, and clinical evidence is limited $[7,11,12]$. Some studies have shown evidence of an existing relationship between the elevation of the prevalence of dyslipidemia and OSAS, but a clear association has not yet been found $[2,4,10-15]$. Dyslipidemia and OSAS severity could be related, higher levels of dyslipidemia being associated with increased Apnea/Hypopnea Index (AHI) [2]. As such, reinforcing cardiovascular prevention of dyslipidemia and acting therapeutically could be important in improving cardio-vascular health associated with OSAS [5]. 


\section{Objectives}

The aim of this study was to evaluate the prevalence of dyslipidemia as a comorbidity associated with OSAS and to understand its relationship with the severity of OSAS and its complications.

\section{Material and methods}

This was an observational cross-sectional study involving a target population of patients with Obstructive Sleep Apnea Syndrome (OSAS) followed in a General Practice and Family Medicine setting from two Primary Care Units in Central Portugal in 2016.

As exclusion criteria: patients with the P06 International Classification for Primary Care2 (ICPC2) code who were not treated using continuous positive airway pressure (CPAP) and patients with other types of sleep disturbance (insomnia, hypersomnia, nightmares and sleepwalking). Data was gathered from randomly selected e.processes from the patient lists of both health units using the mim@uf program until obtaining the needed sample. In the second stage, the same data was collected for controls (without OSAS) using random lists paired in age and gender with the cases of OSAS.

A questionnaire with the variables under study was used, including:

- gender,

- age (years),

- Body Mass Index (BMI) in $\mathrm{kg} / \mathrm{m}^{2}$ registered in the process,

- dyslipidemia/lipids metabolism coded on the list of problems (T93)

- Arterial Hypertension (HTA) coded in the list of problems (K86),

- type 2 Diabetes Mellitus (DM) coded in the list of problems (T90),

- total cholesterol, LDL, HDL and triglycerides values,

- Apnea/Hypopnea Index (AHI) registered in the process (only for the cases),

- anti-dyslipidemia drugs prescribed during the last 6 months,

- questionnaire with the variables under study:

Mild OSA: IAH $=5.0-15.0 / \mathrm{h}$

Moderate OSA: $I A H=15.1-30.0 / \mathrm{h}$,

Severe OSA: $\mid A H>30.0 / \mathrm{h}$.

Data was collected from October to December 2016 after its approval by the Ethics Commission of ARS Center and authorizations from the Health Units.

Qualitative measures were described using absolute and relative frequencies, and the quantitative measures were described by their average and standard deviation when normally distributed.

Student's $t$-test was used for independent numeric variables in the groups with and without OSAS. A bivariate analysis was performed between OSAS and each of the associated comorbidities (overweight, arterial hypertension and diabetes mellitus) and between dyslipidemia and $\mathrm{AHI}$.

A multivariate analysis by logistic regression was performed to evaluate the independent relationship between each of the comorbidities and OSAS, determining the respective relative risks. Any value of $p<0.05$ was considered statistically significant.

\section{Results}

The sample of 92 OSAS cases and 184 controls used in this study was mostly made up of male individuals $(74 \%)$ aged between 35 and 89 . The average age was $63.763 .7 \pm 10.3$ years (Table 1). No significant statistical differences were found between the group of patients with OSAS and the group without OSAS for gender and age.

\begin{tabular}{|c|c|c|c|}
\hline Parameters & Cases $(n=92)$ & Controls $(n=184)$ & $p$ \\
\hline Gender (M:F) & 68 (74\%):24 (26\%) & $136(74 \%): 48(26 \%)$ & 1 \\
\hline Average age & $63.7 \pm 10.3$ & $63.7 \pm 10.3$ & 1 \\
\hline Minimum age & 35 & 35 & 1 \\
\hline Maximum age & 89 & 89 & 1 \\
\hline
\end{tabular}

The data is presented by absolute frequency and proportion or average and standard deviation. Chi-squared and Student's $t$-test tests were used for independent samples.

The data is presented by absolute frequency and proportion or average and standard deviation. Chi-squared and Student's $t$-tests were used for independent samples.

In a bivariate analysis, significant statistical differences were observed in all comorbidities between the group of patients with OSAS and without OSAS. The most frequent comorbidities in patients with OSAS were overweight $(97 \%)$, arterial hypertension (89\%) and dyslipidemia (80\%). Type 2 diabetes mellitus was found in $43 \%$ of the patients (Table 2 ).

\begin{tabular}{|c|c|c|c|}
\hline Parameters & OSAS $(n=92)$ & Controls $(n=184)$ & $p$ \\
\hline Overweight & 89 (97\%) & $148(81 \%)$ & $<0.001$ \\
\hline $\begin{array}{l}\text { Arterial hyper- } \\
\text { tension }\end{array}$ & $82(89 \%)$ & $125(68 \%)$ & $<0.001$ \\
\hline Dyslipidemia & $74(80 \%)$ & $110(60 \%)$ & $<0.001$ \\
\hline $\begin{array}{l}\text { Type } 2 \text { diabetes } \\
\text { mellitus }\end{array}$ & $39(43 \%)$ & $42(23 \%)$ & $<0.001$ \\
\hline
\end{tabular}

The data is presented by absolute frequency and proportion. The chisquared test was used.

A multivariate analysis to study the relationship of OSAS with each of the associated comorbidities (overweight, HTA, type 2 diabetes mellitus and dyslipidemia) was carried out. OSAS was not independently related to diabetes mellitus type $2(p=0.101)$ and to dyslipidemia $(p=0.389)$. However, overweight and arterial hypertension were independently related with OSAS, with a relative risk of having OSAS of 5.51 and of 2.73 , respectively.

Table 3. Multivariate analysis by logistic regression of associated comorbidities independently of OSA

\begin{tabular}{|l|l|l|l|l|}
\hline Parameters & $\boldsymbol{p}$ & RR & $\begin{array}{l}\text { Cl 95\% } \\
\text { inferior }\end{array}$ & Superior \\
\hline Overweight & 0.007 & 5.51 & 1.6 & 19.02 \\
\hline $\begin{array}{l}\text { Arterial hyper- } \\
\text { tension }\end{array}$ & 0.014 & 2.73 & 1.2 & 6.1 \\
\hline
\end{tabular}

Patients with OSAS were more often on medical treatment for dyslipidemia $(92 \%)$ when compared to controls $(84 \%, p \leq 0.001)$.

According to $\mathrm{AHI}$, patients were distributed by severity (Table 4).

\begin{tabular}{|l|l|}
\hline \multicolumn{2}{|l|}{ Table 4. OSAS case distribution according to severity } \\
\hline Apnea/Hypopnea Index & Cases (\%) \\
\hline$<5$ & $16(27 \%)$ \\
Mild $(\geq 5$ and $<15)$ & $16(27 \%)$ \\
Moderate $(\geq 15$ and $<30)$ & $12(19 \%)$ \\
Severe $(\geq 30)$ & $16(27 \%)$ \\
\hline
\end{tabular}

$\mathrm{AHI}<5$; mild: $\geq 5$ and < 15; moderate: $\geq 15$ and < 30; severe: $\geq 30$. The data is presented by absolute and standard deviation frequency. $n=60$. 
Table 5 shows the prevalence of dyslipidemia, distributed by the severity of OSAS, estimated by AHI. No statistically significant differences were observed in the presence of dyslipidemia among the patients with different levels of severity using the chi-squared test. The prevalence of dyslipidemia was lower in patients with moderate OSAS (13\%) compared to patients with $\mathrm{AHI}<5(20 \%)$ and mild OSAS (22\%).

\begin{tabular}{|c|c|c|c|c|c|}
\hline $\begin{array}{l}\text { Parameters/ } \\
\text { /AHI }\end{array}$ & $<5$ & Mild & Moderate & Severe & $\sqrt{p}$ \\
\hline Dyslipidemia & $20 \%$ & $22 \%$ & $13 \%$ & $25 \%$ & 0.322 \\
\hline
\end{tabular}

Absence of OSA: $<5$; OSA presence: $>5$ : mild: $\geq 5$ and $<15$; moderate: $\geq$ 15 and $<30$; severe: $\geq 30$. The data is presented by absolute frequency in percentage. $n=60$. The chi-squared test was used.

\section{Discussion}

As was reported in other studies, we found that overweight, arterial hypertension and diabetes mellitus type 2 were associated with OSAS $[5,6,10,17]$. Overall, these values were higher than those described in other studies $[5,6,10,17]$. Such a fact might be explained by the reduced size of the sample and possible bias in the selection of patients from only two health units used in the sample collection.

It has been shown that overweight plays an important role in the development of OSAS $[5,14]$. In this sample with OSAS, $97 \%$ were overweight, a higher prevalence than previously [14]. The prevalence of overweight was significantly more frequent in patients with OSAS. It is described that $40 \%$ of patients with OSAS have arterial hypertension, but this value could be higher if we consider the fact that some patients with arterial hypertension are thought to have hidden OSAS [14]. A type 2 diabetes mellitus prevalence of $43 \%$ was found, significantly higher in patients with OSAS. OSAS can be involved in the pathogenesis of glucose metabolism alteration [14].

The prevalence of dyslipidemia in OSAS patients in this study is higher than the values found in patients without OSAS, with significant statistical differences in bivariate analysis. For this association, studies are scarce, and evidence is limited [7, 12]. Some studies show a relationship between dyslipidemia and the prevalence of OSAS $[2,4,10-15,18]$, although a clear association has not yet been shown $[2,4,12,13,15]$.

A multivariate analysis was carried out in order to exclude confounding variables. A significant independent relationship was found between OSAS and overweight (OSAS risk 5.51 times higher) and between OSAS and arterial hypertension (OSAS risk 2.73 times higher).

As for type 2 diabetes mellitus, its relation to OSAS was not independent from the other factors, although the prevalence of type 2 diabetes mellitus was higher in patients with OSAS. This was reversed when the confounding factors were adjusted, as was seen in other studies [10].

In the multivariate analysis, there was no significant and independent association between dyslipidemia and OSAS, which might reinforce the hypothesis of OSAS not being independently related to dyslipidemia. However, its presence in these patients might be better explained by an association with other present comorbidities (overweight, arterial hypertension and diabetes mellitus type 2). The state of insulin resistance is a mechanism that might be present in the development of the previous comorbidities, particularly in the origin of metabolic syndrome [19-22]. Some studies even suggest OSAS as being one of the components of metabolic syndrome [10], classifying it as syndrome $Z[10,14,19,23]$. Thus, the dyslipidemia which occurs in a patient with OSAS can be related to the metabolic alterations that lead to the development of atherosclerosis, worsening cardiovascular outcomes [21]. The fact that treatment with CPAP has shown a mild improvement in metabolic changes [12, 18, 24-27] might explain the fact that these may not be directly associated to OSAS. Other studies state that night chronic hypoxemic state, present in OSAS, is independently related with dyslipidemia [4] in spite of limited evidence [15].

Previous studies have shown that dyslipidemia might be related to the severity of OSAS $[2,7]$. In this study, this possible relationship was evaluated using AHI. No statistical differences were observed between the prevalence of dyslipidemia and the different degrees of severity of OSAS $(<5$, light, moderate and severe). The prevalence of dyslipidemia in OSAS patients with $\mathrm{AHI}<5$ was $20 \%$, in mild OSAS $-22 \%$, and in severe OSAS $-25 \%$, meaning that the prevalence might increase with the severity of OSAS. However, in the case of moderate OSAS, the prevalence of dyslipidemia was only $13 \%$. These results were also found in other studies [2]. This might be explained by the reduced sample size, by the high levels of omissions of registration of the $\mathrm{AHI}$ parameter and by the fact that there was a small number of patients with moderate OSAS. As mentioned before, as well as in other studies, the confounding factors (overweight, arterial hypertension and diabetes mellitus) may represent a determining role in the lipid profile of patients and in the different stages of OSAS severity $[2,7]$.

As for limitations of this study, one must bear in mind the reduced size of the sample, even though it was calculated to be representative of the population. We studied a mostly male sample, which is in accordance with previous studies $[2,5,6]$. The average age was $63.7 \pm 10.0$ years, an older age than most other studies described $[2,5,6]$. This fact might be explained by underdiagnosed OSAS in Portugal or be the consequence of a late diagnosis [5].

Another limitation could be the fact that the information recorded in the electronic clinical processes might not be correct or was missing, namely for the Apnea/Hypopnea Index (IAH). Future studies will be needed to better explain this relationship in larger samples and while excluding possible confounding factors.

\section{Conclusions}

In our sample, patients with OSAS had a higher prevalence of dyslipidemia which was not independent from other cardiovascular risk factors. Dyslipidemia might be better explained in OSAS patients in a context of associated overweight and cardiovascular risk. Dyslipidemia and OSAS severity were not statistically associated.

Source of funding: This work was funded from the authors' own resources.

Conflicts of interest: The authors declare no conflicts of interest.

\section{References}

1. Miller J, Berger A. Screening and assessment for obstructive sleep apnea in primary care. Sleep Med Rev 2016; 29: 41-51, doi: 10.1016/j. smrv.2015.09.005.

2. Nadeem R, Singh M, Nida M, et al. Effect of obstructive sleep apnea hypopnea syndrome on lipid profile: a meta-regression analysis. J Clin Sleep Med 2014; 10(5): 475-489, doi: 10.5664/jcsm.3690. 
3. Balta S, Aydogan M, Demirkol S, et al. Nocturnal intermittent hypoxemia and metabolic dyslipidemia. Chest 2013; 144(1): 357, doi: 10.1378/chest.12-3109.

4. Drager LF, Jun J, Polotsky VY. Obstructive sleep apnea and dyslipidemia: implications for atherosclerosis. Curr Opin Endocrinol Diabetes Obes 2010; 17(2): 161-165, doi: 10.1097/MED.0b013e3283373624.

5. Rodrigues A, Pinto P, Nunes B, et al. [Obstructive Sleep Apnea Syndrome: Epidemiology and Portuguese patients profile]. Rev Port Pneumol 2017; 23(2): 57-61, doi: 10.1016/j.rppnen.2017.01.002 (in Portuguese).

6. Pipa J. A importância do diagnóstico do síndrome de apneia obstrutiva do sono na prevenção das doenças cardiovasculares [dissertation]. Porto: University of Porto; 2009 (in Portuguese).

7. Guan J, Yi H, Zou J, et al. Distinct severity stages of obstructive sleep apnoea are correlated with unique dyslipidaemia: large-scale observational study. Thorax 2016; 71(4): 347-355, doi: 10.1136/thoraxjnl-2015-207403.

8. Fundação Portuguesa de Cardiologia. Dislipidemia. Lisbon; 2017 [cited 5.01.2017]. Available from URL: http://www.fpcardiologia.pt/ saude-do-coracao/factores-de-risco/dislipidemia/ (in Portuguese).

9. Bordalo A, Carvalho AA, Oliveira AL, et al. [The Health of the Portuguese. Perspective 2015]. Lisboa: DGS; 2015 (in Portuguese).

10. Stansbury R, Strollo P. Clinical manifestations of sleep apnea.J Thorac Dis 2015; 7(9): 298-310, doi: 10.3978/j.issn.2072-1439.2015.09.13.

11. Adedayo AM, Olafiranye $O$, Smith $D$, et al. Obstructive sleep apnea and dyslipidemia: evidence and underlying mechanism. Sleep Breath 2014; 18(1): 13-18, doi: 10.1007/s11325-012-0760-9.

12. Carneiro G, Fontes FH, Togeiro SM. [Metabolic consequences of untreated obstructive sleep apnea syndrome]. J Bras Pneumol 2010; 36(Suppl. 2): 43-46, doi: 10.1590/s1806-37132010001400012 (in Portuguese).

13. Chou YT, Chuang LP, Li HY, et al. Hyperlipidaemia in patients with sleep-related breathing disorders: prevalence \& risk factors. Indian J Med Res 2010; 131: 121-125.

14. Jean-Louis G, Zizi F, Clark LT, et al. Obstructive sleep apnea and cardiovascular disease: role of the metabolic syndrome and its components. J Clin Sleep Med 2008; 4(3): 261-272.

15. Jun J, Polotsky VY. Metabolic consequences of sleep-disordered breathing. ILAR J 2009; 50(3): 289-306, doi: 10.1093/ilar.50.3.289.

16. Epstein LJ, Kristo D, Strollo PJ, et al. Clinical guideline for the evaluation, management and long-term care of obstructive sleep apnea in adults. JCSM 2009; 5(3): 263-276.

17. Hasan A, Uzma N, Swamy TL, et al. Correlation of clinical profiles with obstructive sleep apnea and metabolic syndrome. Sleep Breath 2012; 16(1): 111-116, doi: 10.1007/s11325-010-0463-z.

18. Rebelo S, Drummond M, Marques JA. Lipid profile after long-term APAP in OSA patients. Sleep Breath 2015; 19(3): 931-937, doi: 10.1007/s11325-014-1095-5.

19. Kono M, Tatsumi K, Saibara T, et al. Obstructive sleep apnea syndrome is associated with some components of metabolic syndrome. Chest 2007; 131(5): 1387-1392, doi: 10.1378/chest.06-1807.

20. Liu A, Cardell J, Ariel D, et al. Abnormalities of lipoprotein concentrations in obstructive sleep apnea are related to insulin resistance. Sleep 2015; 38(5): 793-799, doi: 10.5665/sleep.4678.

21. Lin QC, Chen LD, Yu YH, et al. Obstructive sleep apnea syndrome is associated with metabolic syndrome and inflammation. Eur Arch Otorhinolaryngol 2014; 271(4): 825-831, doi: 10.1007/s00405-013-2669-8.

22. Lin QC, Zhang XB, Chen GP, et al. Obstructive sleep apnea syndrome is associated with some components of metabolic syndrome in nonobese adults. Sleep Breath 2012; 16(2): 571-578, doi: 10.1007/s11325-011-0544-7.

23. Seetho IW, Wilding JP. Sleep-disordered breathing, type 2 diabetes and the metabolic syndrome. Chron Respir Dis 2014; 11(4): 257-275 , doi: $10.1177 / 1479972314552806$.

24. Lurie A. Metabolic disorders associated with obstructive sleep apnea in adults. Adv Cardiol 2011; 46: 67-138, doi: 10.1159/000325106.

25. Feres MC, Fonseca FA, Cintra FD, et al. An assessment of oxidized LDL in the lipid profiles of patients with obstructive sleep apnea and its association with both hypertension and dyslipidemia, and the impact of treatment with CPAP. Atherosclerosis 2015; 241(2): 342-349, doi: 10.1016/j.atherosclerosis.2015.05.008.

26. Monahan K, Redline S. Role of obstructive sleep apnea in cardiovascular disease. Curr Opin Cardiol 2011; 26(6): 541-547, doi: 10.1097/ HCO.0b013e32834b806a.

27. $\mathrm{Xu} \mathrm{H,} \mathrm{Yi} \mathrm{H,} \mathrm{Guan} \mathrm{J,} \mathrm{et} \mathrm{al.} \mathrm{Effect} \mathrm{of} \mathrm{continuous} \mathrm{positive} \mathrm{airway} \mathrm{pressure} \mathrm{on} \mathrm{lipid} \mathrm{profile} \mathrm{in} \mathrm{patients} \mathrm{with} \mathrm{obstructive} \mathrm{sleep} \mathrm{apnea} \mathrm{syndrome:}$ a meta-analysis of randomized controlled trials. Atherosclerosis 2014; 234(2): 446-453, doi: 10.1016/j.atherosclerosis.2014.03.034.

Tables: 5

Figures: 0

References: 27

Received: 27.03 .2020

Reviewed: 30.03 .2020

Accepted: 30.04 .2020

Address for correspondence:

José Augusto Simões, MD, PhD, Assoc. Prof.

Faculty of Health Sciences

University Beira Interior

Rua Teofilo Braga, 25, 5 Dto

3030-076 Coimbra

Portugal

Tel.: +351924406127

E-mail: jars@fcsaude.ubi.pt 